\title{
Unabiara, um novo gênero de Heteropsini Lacordaire, 1869 (Coleoptera, Cerambycidae) ${ }^{1}$
}

\author{
Dilma Solange Napp ${ }^{2,4}$ \\ Ubirajara R. Martins ${ }^{3,4}$
}

\begin{abstract}
Unabiara, a new genus of Heteropsini Lacordaire, 1869 (Coleoptera, Cerambycidae). Unabiara gen. nov. is proposed to include Callideriphus collaris Philippi \& Philippi, 1864 (type species); provisionally it is maintained in Heteropsini Lacordaire, 1869. Unabiara collaris (Philippi \& Philippi, 1864) new combination, is redescribed and illustrated, including the mouth pieces, endosternites, wing venation and male and female terminalia.
\end{abstract}

Keywords. Cerambycinae; Heteropsini; new genus; taxonomy; Unabiara.

\section{INTRODUÇÃO}

O estudo do gênero Callideriphus Blanchard, 1851 permitiu reconhecer que $C$. collaris Philippi \& Philippi, 1864, não pertence ao gênero e, por esta razão, Unabiara gen. nov. é proposto para abrigá-la. Muitos dos caracteres anatômicos presentes no novo gênero são conflitantes com os reconhecidos para a tribo Heteropsini Lacordaire, 1869. Entretanto, na falta de um estudo mais abrangente das tribos neotropicais de Cerambycinae com olhos finamente facetados, Unabiara é provisoriamente mantido nesta tribo.

Siglas mencionadas referem-se às seguintes instituições: Departamento de Zoologia, Universidade Federal do Paraná, Curitiba (DZUP); Museo Nacional de Historia Natural, Santiago (MNCC); Museu Nacional, Universidade Federal do Rio de Janeiro, Rio de Janeiro (MNRJ); Museu de Zoologia, Universidade de São Paulo, São Paulo (MZSP).

\section{Unabiara gen. nov.}

Espécie-tipo: Callideriphus collaris Philippi \& Philippi, 1864.

Etimologia Tupi: una $=$ besouro e abyara $=$ diferente.

Pequenas dimensões (comprimento, 5,2-7,7 mm). Forma estreita, alongada. Cabeça (Fig. 5): fronte curta, transversa, plana, declive, não deprimida entre os tubérculos anteníferos, estes arredondados; alvéolos antenais pequenos e distantes da inserção das mandíbulas; vértice abaulado, em nível superior ao dos lobos oculares superiores; genas mais curtas que a metade do diâmetro de um lobo ocular inferior; submento com projeção curta e transversa entre as maxilas; suturas gulares pouco alongadas e convergentes. Olhos finamente facetados, pouco emarginados; lobos inferiores bem desenvolvidos ocupam toda a região lateral da cabeça; lobos superiores largos, com cerca da metade da largura dos lobos inferiores, a distância entre os superiores cerca de 2 vezes o diâmetro de um lobo; faixa de ligação entre os lobos tão larga quanto um lobo superior. Mandíbulas (Fig. 1) delgadas, de secção triangular, arredondadas na face lateral externa, os ápices aguçados; bordo cortante com pequeno dente no terço anterior e com franja de pêlos. Maxilas (Fig. 2): estipe transverso, fortemente esclerotinizado, distintamente dividido em base- e mesostipe; gálea capitada, retrátil e com anel esclerotinizado na base, alcança o terço basal do artículo apical do palpo; lacínia desenvolvida; artículo apical dos palpos maxilares, cilíndrico, atenuado e truncado no ápice, tão longo quanto os dois precedentes somados; artículo 2 mais longo que o 3. Lábio (Figs. 3, 4): mento fortemente esclerotinizado; lígula membranosa, chanfrada em ângulo obtuso, os lobos laterais atingem a base do artículo apical do palpo; com área central fortemente esclerotinizada e com pêlos longos; face interna da lígula com duas faixas de pêlos pouco conspícuas; artículo apical dos palpos como os maxilares.

Antenas com 11 artículos, filiformes, desarmadas, sem sulcos ou carenas, mais curtas que o corpo nos dois sexos; no macho (Figs. 9, 36) atingem o terço apical dos élitros, nas fêmeas (Fig. 10), ultrapassam a metade do corpo. Escapo curto,

1. Contribuição $n^{\circ} 1301$, do Departamento de Zoologia, Universidade Federal do Paraná.

2. Departamento de Zoologia, Universidade Federal do Paraná. Caixa Postal 19020, 81531-990 Curitiba - PR, Brasil.

3. Museu de Zoologia, Universidade de São Paulo. Caixa Postal 42594, 04299-970 São Paulo - SP, Brasil.

4. Pesquisador do CNPq. 
cilíndrico, algo engrossado, um pouco arqueado. Artículos IIIIV com comprimentos subiguais, pouco mais curtos que os $\mathrm{V}$ VI; VIII-XI sensivelmente mais curtos que os III-VI; nas fêmeas os VI-XI decrescentes, os VIII-XI intumescidos.

Protórax (Figs. 6-8) mais longo que largo, pouco e regularmente arredondado aos lados, convexo no dorso. Prosterno com pontuação sexual; região anterior às cavidades coxais tão longa quanto o dobro de uma cavidade cotilóide. Processo prosternal muito estreito, os lados paralelos, levemente expandido no ápice. Cavidades coxais anteriores transversas, fortemente angulosas aos lados, abertas atrás. Coxas anteriores globosas, salientes. Proendosternito (Fig. 8) reduzido, os ápices contíguos, não fusionados. Mesosterno (Fig. 11) plano. Processo mesosternal com cerca da metade do diâmetro de uma cavidade cotilóide média, os lados sem superfícies articulares e convergentes para o ápice, este firmemente justaposto e com entalhe mediano para encaixe do metasterno. Cavidades coxais médias bem desenvolvidas, abertas aos lados. Mesocoxas globosas, salientes. Mesendosternito (Fig. 13) membranoso, a região basal curta, a apical oblíqua em direção ao mesepimero, com ápice livre. Mesoscuto (Fig. 12) com área estridulatória ampla. Metasterno (Fig.15) convexo. Metepisterno esclerotinizado em quase toda a superfície, com carena longitudinal evidente. Metendosternito (Figs. 16-18) com pedúnculo e lâminas laterais alongados, os braços bem mais curtos que as lâminas e perpendiculares ao pedúnculo; lâminas separadas por chanfro mediano raso e moderadamente largo; projeções para implante dos tendões anteriores, reduzidas.

Élitros estreitos e alongados, cerca de três vezes tão longos quanto a largura umeral, esta pouco maior que a maior largura do protórax. Úmeros não projetados. Lados paralelos até os ápices, estes "de per si” um pouco acuminados. Asa (Fig. 14): célula da Radial fechada, triangular; Setor Anterior (SA) sinuosa; Setor (S) evanescente; Média (M) inconspícua; Média Anterior ausente; s-m retilínea; Plical (P), na base, ligeiramente expandida; Ramo A da Empusal (Ea) e 1A + Ea, presentes; lobo anal e veias anais com redução; $2 \mathrm{Aa}$ reduzida. Área carenada na base da Radial, ausente. Árculo bem definido.

Pernas com comprimentos crescentes, as posteriores mais longas que o dobro do comprimento das anteriores. Fêmures (Figs. 19, 21) com clava abrupta na metade apical; sem sulcos ou carenas, as abas apicais arredondadas. Metafêmures distintamente mais curtos que os élitros. Tíbias (Figs. 20, 22) cilíndrico-deprimidas, não carenadas, as anteriores um pouco expandidas para o ápice. Esporões tibiais alongados, o interno mais desenvolvido. Metatarsos (Fig. 25) muito longos, sem escova compacta na face inferior dos tarsômeros; metatarsômero I mais longo que os dois seguintes somados, o III com lobos laterais estreitos e afilados. Empódio (Fig. 23) reduzido, sem cerdas.

Abdômen (Figs. 26, 27) estreito, cilíndrico. Processo intercoxal do urosternito I estreito, acuminado.

Discussão. Unabiara gen. nov. distingue-se de
Callideriphus e dos demais gêneros de Heteropsini pela combinação dos seguintes caracteres: 1) olhos muito desenvolvidos, a ligação entre os lobos bastante larga; 2) cavidades coxais anteriores angulosas aos lados, largamente abertas atrás; 3) cavidades coxais médias abertas aos lados; 4) antenas mais curtas que o corpo nos dois sexos, os artículos apicais mais curtos que os basais; 5) abdômen estreito e cilíndrico; 6) metasterno inflado; 7) artículo apical dos palpos maxilares e labiais cilíndrico, pelo menos tão longo quanto os dois anteriores somados.

\section{Unabiara collaris (Philippi \& Philippi, 1864) comb. nov.} (Figs. 1-36)

Callideriphus collaris Philippi \& Philippi, 1864: 382; Philippi, 1887: 774; Aurivillius, 1912: 444; Blackwelder, 1946: 586; Cerda, 1986: 35; Monné, 1994: 39 (cat.).

Macho. Tegumento preto, brilhante; antenas castanhoamareladas, o escapo e pedicelo mais escuros, até enegrecidos. Todo o corpo, exceto antenômeros III-XI, com abundantes pêlos amarelados, longos e eretos, mais adensados na cabeça, protórax, metade basal dos élitros e pernas. Pubescência branco-amarelada, compacta: na orla posterior do protórax, em toda a superfície do escutelo e dos mesepimeros, em forma de faixa estreita na margem posterior do metasterno que se alarga do sulco mediano para os lados e recobre a parte posterior dos metepisternos, e em forma de mancha a cada lado dos urosternitos II e III.

Cabeça irregularmente pontuado-rugosa, sem pubescência; submento deprimido, pontuado-rugoso e com densa pilosidade longa, ereta. Escapo com pontuação esparsa, sem pubescência; antenômeros III-V com pontuação fina e rasa, pilosidade castanha, decumbente e alguns pêlos longos na face inferior e nos ápices; VI-XI com fina pubescência amarelada, mais adensada para os distais. Pronoto e lados do protórax com pontos grossos, mais esparsos no disco do pronoto; pubescência ausente. Prosterno fina e densamente pontuadorugoso, com pilosidade longa, muito abundante. Metasterno e urosternitos com pontos rasos, esparsos. Élitros com pontos grossos, algo transversos e confluentes, formam rugas transversais irregulares. Pernas esparsamente pontuadas, brilhantes, com abundante pilosidade longa; pilosidade curta ausente nas tíbias. Metatíbias algo sinuosas. Último urosternito (Fig. 27) sinuoso no ápice. Terminália: oitavo esternito (Fig. 29) transverso, fortemente esclerotinizado, bissinuado no bordo apical e provido com pêlos muito longos, apófise esternal curta; oitavo tergito (Fig. 28) mais longo que largo, aspecto octogonal, com abundantes pêlos longos e sinuosos nas margens apical e laterais. Arco ventral (Fig. 30) com apófise alongada e região basal bifurcada, curta; arco dorsal (Fig. 30) bem desenvolvido, esclerotinizado, pontuado e com pêlos numerosos. Tégmen (Fig. 31) com lobos laterais longos, cilíndricos; peça anelar convergente na região anterior, os braços unidos, parcialmente fusionados. Lobo médio (Fig. 32) com os lobos dorsal e ventral 

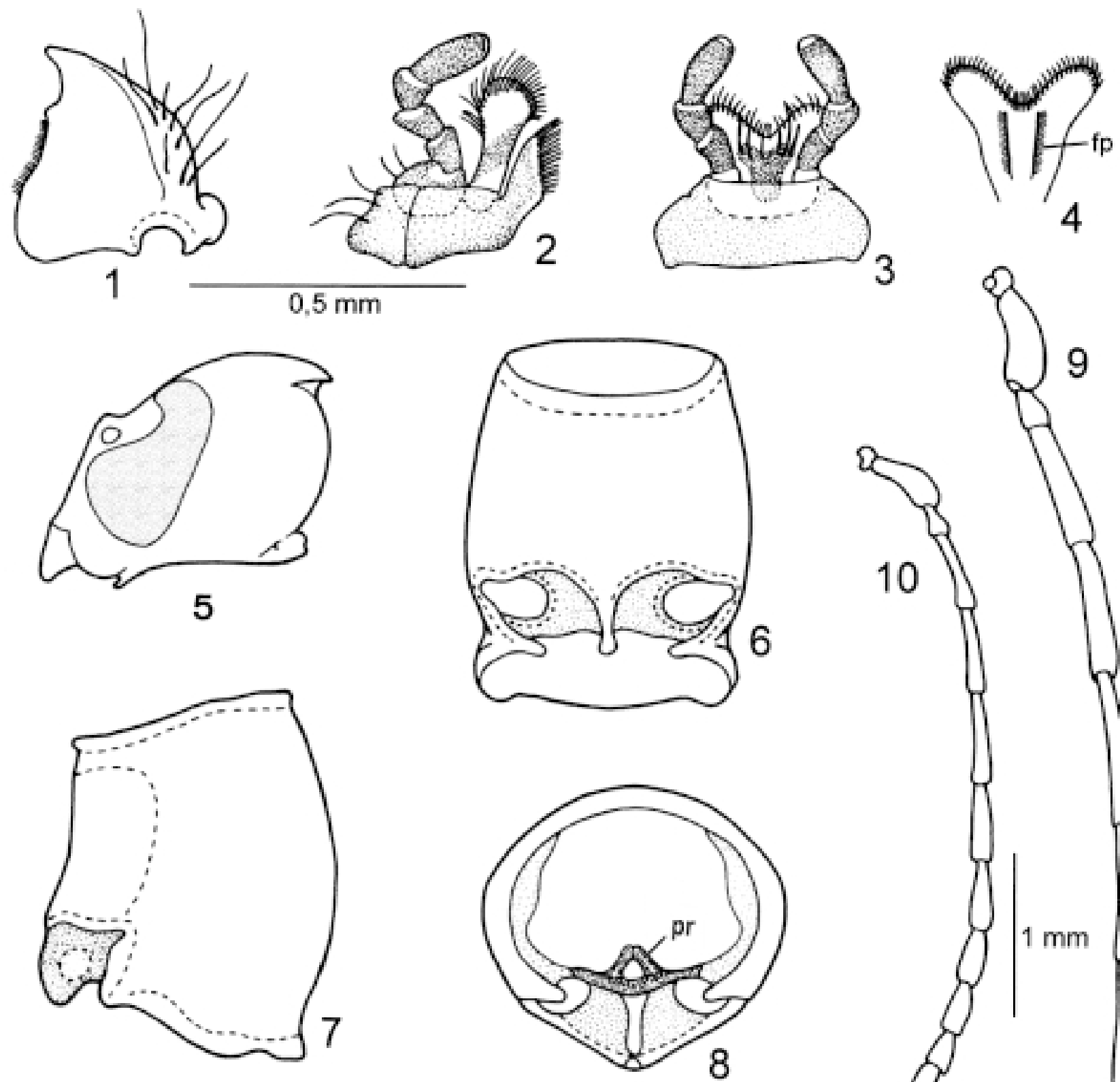

$1 \mathrm{~mm}$
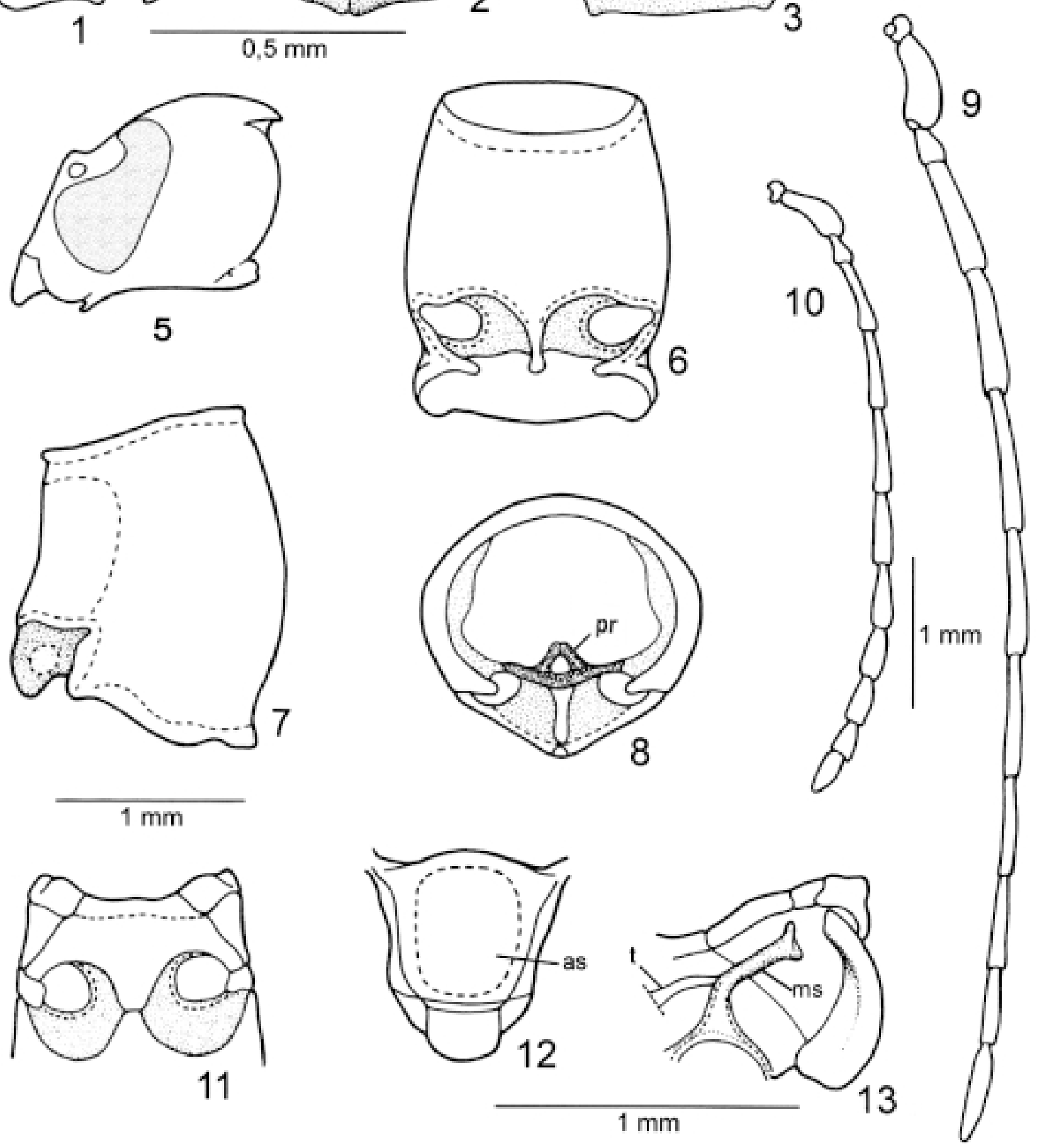

$1 \mathrm{~mm}$

Figs. 1-13. Unabiara collaris (Philippi \& Philippi, 1864). 1, mandíbula; 2, maxila; 3, lábio; 4, face interna da lígula; 5, cabeça, lateral; 6-8, protórax, ventral, lateral e posterior; 9, antena, macho; 10, antena, fêmea; 11, mesosterno; 12; mesoscuto; 13, mesendosternito; as = área estridulatória; fp = franja de pêlos; $\mathrm{ms}=$ mesendosternito; $\mathrm{pr}=$ proendosternito; $\mathrm{t}$ = tendão. Figs.1-4, 5-8 e 11, 9-10 e 12-13, respectivamente, na mesma escala. 

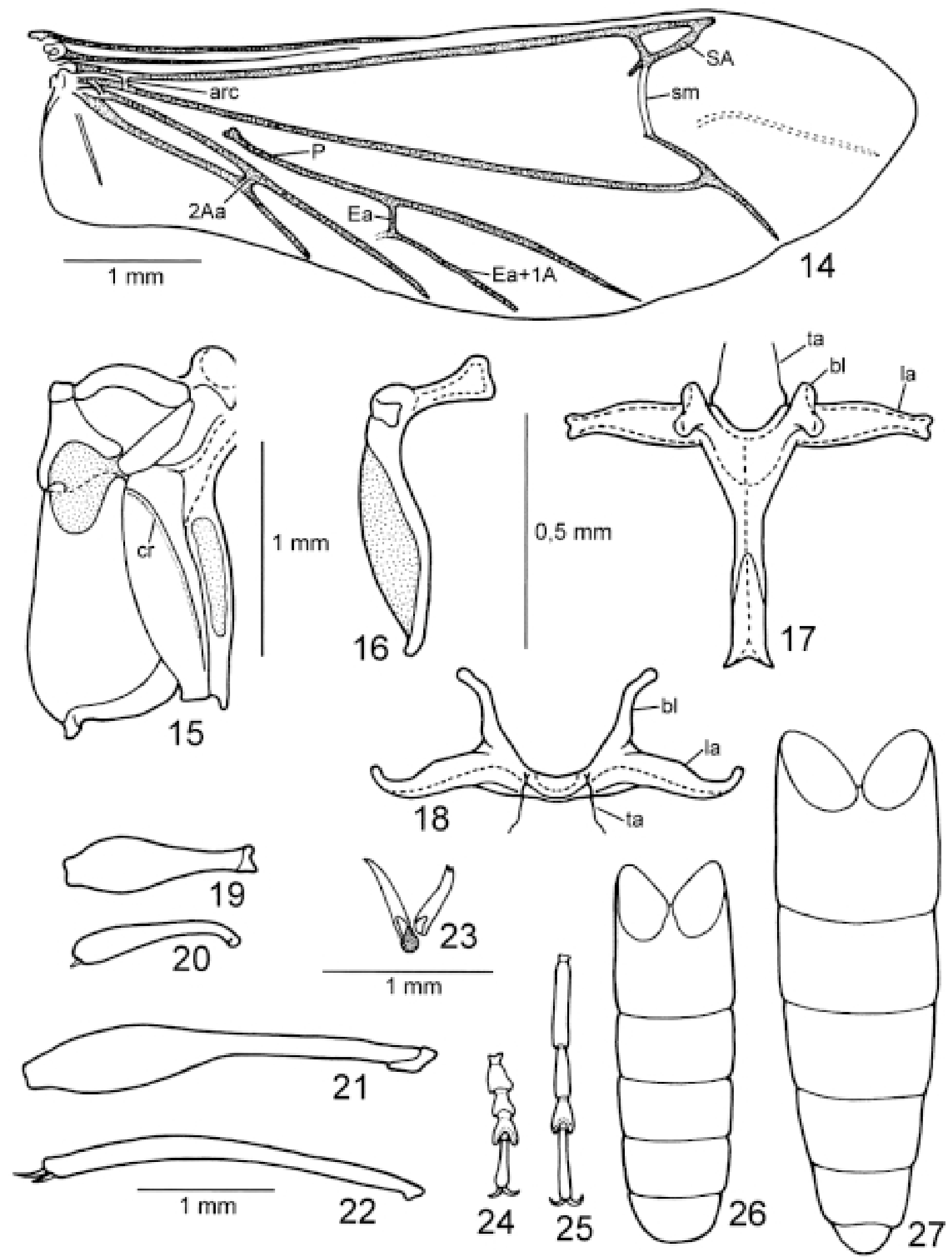

Figs. 14 - 27. Unabiara collaris (Philippi \& Philippi, 1864). 14, asa; 15, meso- e metasterno, lateral; 16-18, metendosternito, vistas lateral, dorsal e anterior; 19, profêmur; 20, protíbia; 21, metafêmur; 22, metatíbia; 23, empódio; 24, protarso; 25, metatarso; 26, abdômen, fêmea; 27, abdômen, macho; arc = árculo; $\mathrm{bl}=$ braços laterais; $\mathrm{cr}=$ carena do metepisterno; $\mathrm{Ea}=$ ramo a da Empusal; la = lâminas laterais; $\mathrm{P}=\mathrm{Plical} ; \mathrm{SA}=\mathrm{Setor}$ Anterior; $\mathrm{s}-\mathrm{m}=$ transversa setor-média; $\mathrm{ta}=$ tendões anteriores; $1 \mathrm{~A}=1 \mathrm{a}$. anal; $2 \mathrm{Aa}=$ ramo a da $2 \mathrm{a}$. anal. Figs. $14,19-22$ e 24-27, na mesma escala. 

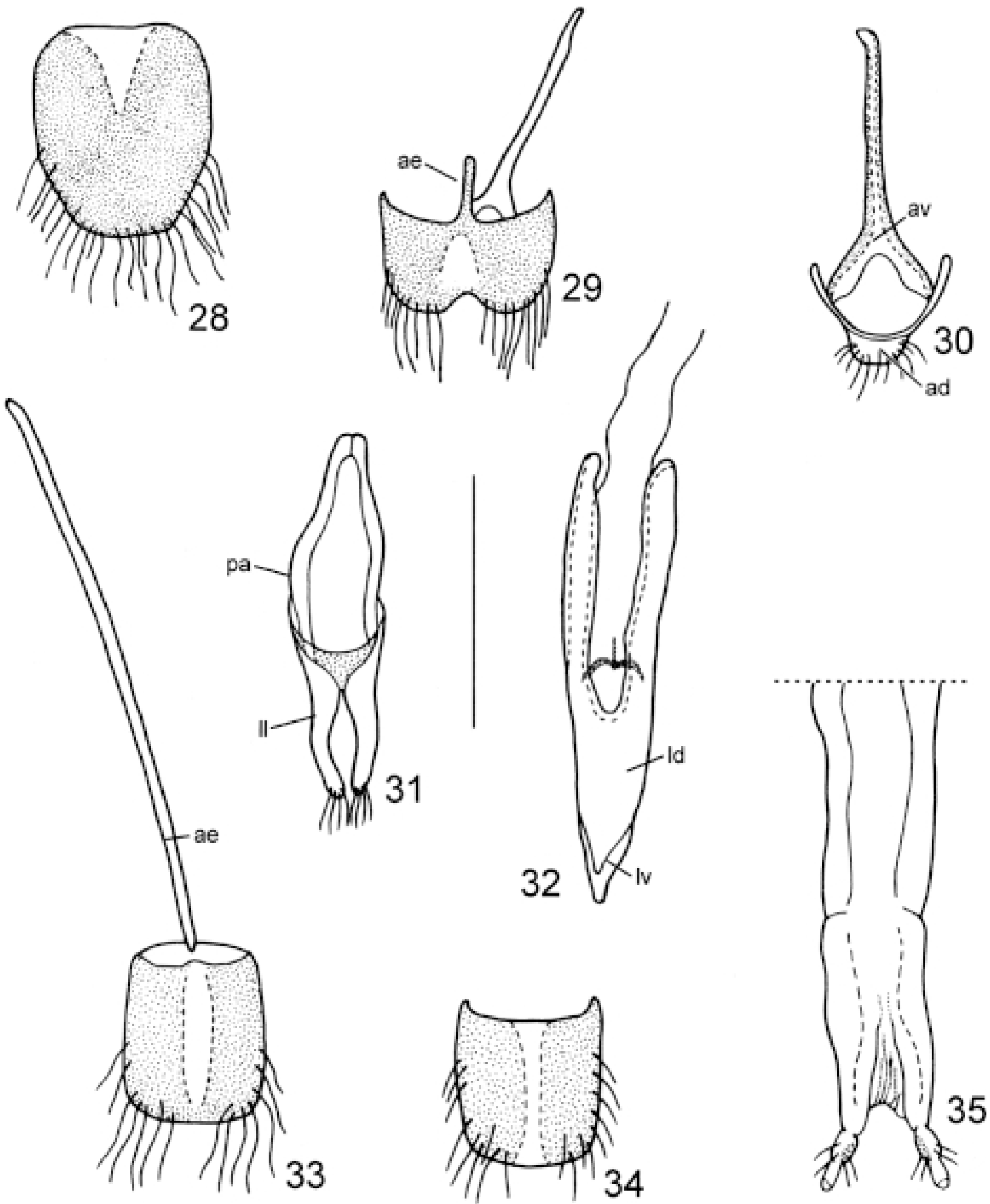

Figs. 28 - 35. Unabiara collaris (Philippi \& Philippi, 1864). 28-32, terminália do macho: 28, oitavo tergito; 29, oitavo esternito; 30, arco ventral e dorsal; 31, tégmen; 32, lobo médio. 33-35, terminália da fêmea: 33, oitavo esternito; 34, oitavo tergito; 35, ovipositor; ad = arco dorsal; ae $=$ apófise esternal; av = arco ventral; $1 \mathrm{~d}=$ lobo dorsal; $1 \mathrm{l}=$ lobos laterais; $1 \mathrm{v}=$ lobo ventral; pa = peça anelar. Barra $=1 \mathrm{~mm}$. 


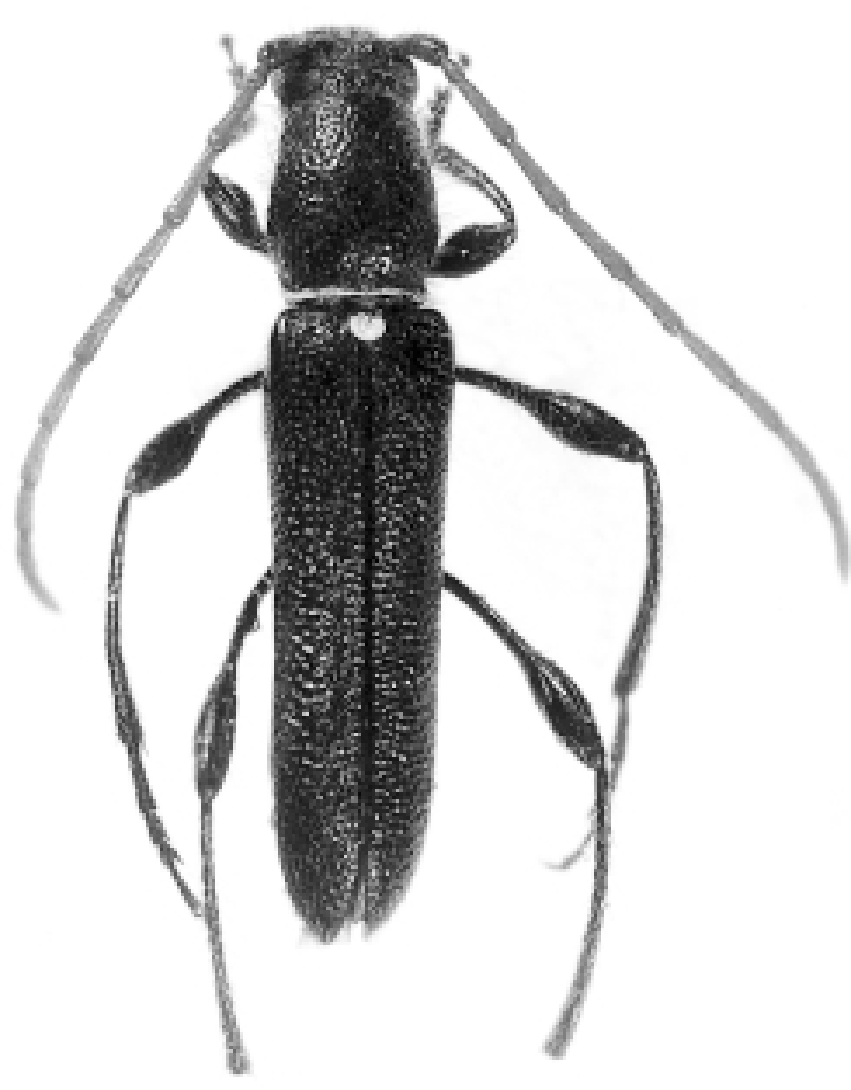

Fig. 36. Unabiara collaris (Philippi \& Philippi, 1864), macho, Chile, Santiago, San José de Maipo, M. Elgueta leg., comprimento, 6,5 mm. A. M. Sakakibara, foto.

acuminados no ápice, o dorsal mais curto; saco interno sem peças esclerotinizadas ou espículos.

Fêmea. Antenas (Fig. 10) alcançam a metade do comprimento dos élitros; antenômeros III-V com comprimentos subiguais, mais longos que os demais; VI-X decrescentes, mais evidentemente os VIII-X, intumescidos; XI apenas mais longo que X. Prosterno brilhante, pontuado-rugoso, a pilosidade mais esparsa do que no macho. Metafêmures mais delgados e evidentemente mais curtos que os élitros. Último urosternito (Fig. 26) truncado-arredondado no ápice. Terminália: oitavo segmento (Figs. 33, 34) pouco mais longo que largo, de lados subparalelos e ápice truncado-arredondado; apófise esternal cerca de três vezes mais longa que o esternito. Ovipositor (Fig. 35) membranoso, alongado; estilos apicais.

Dimensões, mm, macho/fêmea, respectivamente. Comprimento total, 7,7-5,2/7,5-5,7; comprimento do protórax, $1,8-1,3 / 1,8-1,2$; largura do protórax, $1,6-0,8 / 1,5-1.0$; comprimento do élitro, 5,3-3,5/5,2-4,0; largura umeral, $1,8-$ $1,0 / 1,7-1,2$.

Material-tipo. Não examinado. De acordo com HoRn \& KAHLE (1936) o material-tipo encontra-se depositado no MNCC. A descrição original foi baseada, aparentemente, em único exemplar, proveniente da Província de Santiago (Chile), embora os autores acrescentem “... non valde rarus.” (PHILIPPI \& PHILIPPI 1864).

Material examinado. CHILE, $1 \mathrm{M}, 19 . X I .944$, Gutierrez leg., $1 \mathrm{M}$ 24.I.1939, 2 M, Kuschel leg. (MNRJ). Santiago: El Ingenio, 1 M, 1 F, 29.XI.1975, D. Jackson leg. (MNRJ); Santiago (San José de Maipo), 1 M, 9.XII.1972, M. Elgueta leg. (MNCC); Til-Til (Caleu) 2 M, 1 F, 18.I.1987, Cerda leg. (MZSP), (Lo Marin), 1 M, 11.XII.1983, Cerda leg. (MZSP). Valparaíso: Colliguay, 3 M, 2 F, 29.XII.1977, Cerda leg. (MZSP, DZUP); Placilla, 1 M, 2 F, XII.1990, L. Peña leg. (MZSP); Viña del Mar, 1 M, XI.1952, Monsalve leg. (MZSP). Coquimbo: Illapel, 1 M, 30.II.1972 (DZUP). Limache: La Dormida, 1 M, 10.IX.1980, T. Curkovic leg. (MNCC).

\section{REFERÊNCIAS}

Aurivillius, C. 1912. Coleopterorum Catalogus, pars 39, Cerambycidae: Cerambycinae. Berlin, W. Junk, 574 p.

Blackwelder, R. E. 1946. Checklist of the Coleopterous insects of Mexico, Central America, the West Indies and South America. Bulletin of the United States National Museum 185(4): 551-753.

Cerda, M. 1986. Lista sistemática de los cerambícidos Chilenos (Coleoptera: Cerambycidae). Revista Chilena de Entomologia 14: 29-39.

Horn, W. \& I. Kahle. 1936. Über entomologische Sammlungen, Entomologen \& Entomo-Museologie. Entomologische Beihefte Berlin-Dahlem 3: 162-296.

LACORDAiRe, J. T. 1869. Histoire naturelle des insectes. Genera des Coléoptères. Paris, Librairie Encyclopedique de Roret, 9(1): 1409.

Monné, M. A. 1994. Catalogue of the Cerambycidae (Coleoptera) of the western Hemisphere. Part X. São Paulo, Sociedade Brasileira de Entomologia, $81 \mathrm{p}$.

Philippi, F. H. E. 1887. Catálogo de los Coleópteros de Chile. Anales de la Universidad de Chile 71: 619-806.

Philippi, R. A. \& F. H. E. Philippi. 1864. Beischreibung einiger neuen Chilenischen Kafer. Stettiner Entomologische Zeitung 25: 266284; 313-406. 